\title{
Postharvest Ethanol Buildup and Off-flavor in 'Murcott' Tangerine Fruits
}

\author{
Eliahou Cohen, Yavin Shalom, and Ida Rosenberger \\ Department of Fruit and Vegetable Storage, Agricultural Research Organization, The Volcani \\ Center, POB 6, Bet Dagan 50250, Israel
}

Additional index words. citrus, waxes, water loss, ethanol, acetaldehyde

\begin{abstract}
"Abstract. Britex and Zivdar, water-based polyethylene waxes, were applied in commercial and experimental formulations as spray coating, a single dip, or double dips on 'Murcott' tangerine (Citrus reticulate Blanco) fruits. Postharvest waxing of 'Murcott' tangerine reduced weight loss but affected the sensory characteristics of the fruit. Charges in fruit weight loss and juice composition occurred in the waxed fruits after 4 weeks of storage at $5 \mathrm{C}$ plus 1 week of simulated retail handling at $17 \mathrm{C}$. Changes in internal fruit atmosphere were related to fruit flavor quality.
\end{abstract}

'Murcott' is a hybrid tangerine cultivar that has been grown in Israel for almost 15 years. The fruit is flat (oblate) with a yellowish peel and a firm texture. The flesh is tender, very sweet and juicy, and has a very rich flavor. Harvested fruit, however, especially those that are waxed, develop off-flavors regardless of rootstock origin, maturity at harvest, or storage conditions (Cohen et al., 1985). Newhall and Grierson (1955) emphasized the necessity of wax coating citrus to impart a high gloss to the skin and to prevent water loss and shrinkage, thus prolonging the marketing life of fresh fruit. However, Davis et al. (1967, 1973) showed that waxing various citrus fruit cultivars affects respiration and composition of the internal atmosphere, leading to the development of distinct off-flavors.

In studies of physiological changes occurring in citrus fruits during storage, ethanol was found to be the volatile component undergoing the greatest change (Davis and Chace, 1969). Ethanol buildup and off-flavors in juice were found after multiple coatings of either water- or solvent-soluble waxes were applied to oranges. These detrimental effects emphasize the dangers of overtaxing (Davis and Hoffmann, 1973).

The aim of this study was to determine whether various wax formulations, either those already in use commercially or those experimentally produced for coating "easy-to-peel" fruits, differ in their influence on physiological, chemical, and sensory characteristics of 'Murcott' tangerines during storage and simulated retail handling (shelf-life).

\section{Materials and Methods}

Fruits. and wax treatments. In 1985-86 'Murcott' tangerines were taken from two packinghouses. Fruits were spray-coated in a packinghouse system with Britex (Brochar Chemicals, Kfar Saba, Israel) or Zivdar (Safe-Pack Products, Kfar Saba) at 14 $\mathrm{ml}$ wax emulsion $/ \mathrm{kg}$. Both waxes are water-based polyethylene, contain $18 \%$ solid matter, and are used commercially for coating citrus fruit for export. Fruits were stored at $5 \mathrm{C}$ for 2 or 4 weeks, followed by 1 week of simulated retail handling at $17 \mathrm{C}$. Ten packed cartons with 75 fruit in each were taken from each packinghouse.

In 1986-87, 'Murcott' fruit were harvested from a commercial grove and divided at random into 11 groups for treat-

Received for publication 15 Aug. 1989. Contribution from the Agricultural Research Organization, The Volcani Center, Bet Dagan, Israel, no. 2715-E, 1989 series. The cost of publishing this paper was defrayed in part by the payment of page charges. Under postal regulations, this paper therefore must be hereby marked advertisement solely to indicate this fact. ment. In the first six groups, fruits were treated with commercial Britex or Zivdar by spray coating, a momentary single dip, or similar double dips. Four groups were treated with experimental Britex or Zivdar formulations containing either 15\% or $18 \%$ solid matter applied as a single dip. The different modes of wax application are supposed to deposit different amounts of wax on the fruit surface. One group of fruits remained unwaxed and served as the control. All fruits were stored at $5 \mathrm{C}$ for 4 weeks and an additional week of simulated retail handling at $17 \mathrm{C}$.

Chemical analyses. After every storage period, 25 fruits from each treatment were individually weighed to calculate weight (water) loss. Five fruits each in three to four replicates were squeezed in an electric juice extractor with a rotating head to determine juice content expressed on a fresh-fruit weight basis. The juice was analyzed for percent acidity by titration with $\mathrm{NaOH}$. Total soluble solids concentration (SSC) content in the juice was determined with a refractometer. Ethanol and acetaldehyde contents were determined from the head space of a 10-ml aliquot of the juice enclosed in a 50$\mathrm{ml}$ Erlenmeyer flask and incubated on a shaker for $7 \mathrm{~min}$. A l-ml sample of the head space was withdrawn and measured using a gas chromatography. The column was $20 \mathrm{M}$ carbowax TPA on Chromosorb 80/100; the injector was set at 110C, the column at $80 \mathrm{C}$, and the FID detector at $180 \mathrm{C}$. Respiration rate and ethylene production from the fruit were determined by placing 8 to 10 fruits from each treatment in 3-liter jars at $17 \mathrm{C}$ using two to four replicates per treatment. The jars were sealed for $1 \mathrm{hr}$, after which gas samples were removed with a syringe. Carbon dioxide and ethylene concentration were determined by gas chromatography (Model 69-100, GOWMAC Instrument Co., Madison, N.J. ), using a Poropak N column at ambient temperature and a TCD detector for $\mathrm{CO}_{2}$, and an alumina column at 35C and a FID detector for ethylene. The internal $\mathrm{CO}_{2}$, ethanol, and acetaldehyde contents from the internal atmosphere of the fruits were determined by taking gas samples from the intact fruit and analyzing them by gas chromatography, as described.

Taste tests. A panel of six to ten untrained persons was asked to rate the fruit as inedible, edible, or tasty.

\section{Results}

At harvest, $75 \%$ to $87 \%$ of the tasters rated the fruit flavor as tasty. After 2 weeks of storage and 1 week of simulated retail handling, only minor changes occurred in the spraycoated fruit characteristics. For instance, in Britex-coated fruit 
the decrease in acid content and the increases in SSC : acid ratio in ethanol and in acetaldehyde contents in the juice probably were the underlying reasons for fruit being rated as tasty or edible. After 4 weeks of storage and 1 week of simulated retail handling, these changes progressed, with fruit' being rated edible and inedible, rather than tasty. During storage and simulated retail handing, the weight loss of the fruit did not exceed 3. $1 \%$, and respiration rate was between 22.6 and $32.8 \mathrm{mg} \mathrm{CO} / \mathrm{kg}$ per hr (Table 1 ).

Correlation coefficients between compositional characteristics and taste assessments were generally not significant. I-light correlations only were obtained between ethanol and acetaldehyde levels in the juice and flavor rating and between ethanol content and fruit weight loss. For instance, in Britexcoated fruit after 2 weeks of storage and 1 week of simulated retail handling, the correlation coefficient between acetaldehyde in the juice and percentage of tasters who rated the fruit tasty was $(r=0.91)$. After 4 weeks of storage and 1 week of simulated retail handling, a high correlation was obtained between the ethanol level in the juice and edibility $(r-=0.75)$. In Zivdar-coated fruit, a high correlation was obtained between ethanol content and weight loss $(r=-0.85)$.

Differences in the effect of wax formulations and mode of application on weight loss, volatile buildup, and subsequent fruit flavor in comparison with the unwaxed control fruit after 4 weeks of storage and 1 week of simulated retail handling are shown in Table 2. Weight loss in unwaxed 'Murcott' fruit was higher than in waxed fruit. While weight loss in spraycoated fruit was close to that of unwaxed fruit, the most successful prevention of water loss was obtained by double dips in the commercial wax formulations.

Ethanol accumulation was significantly lower in unwaxed fruit than in waxed fruit, while double-dipped fruit had the highest ethanol concentrations. Acetaldehyde content did not vary significantly at $P=0.05$ among treatments (Table 2).

The internal atmosphere of the waxed fruit had a higher $\mathrm{CO}_{2}$ concentration than that of unwaxed fruit. Ethanol level in the spray-coated fruit was almost the same as in the control, and higher in all dip-coated fruit than in unwaxed fruit (Table 2). No appreciable changes were found in the acetaldehyde level of the internal atmosphere of waxed or unwaxed fruits.

The effect of waxing on sensory characteristics of these fruits showed that more tasters rated unwaxed 'Murcott' as tasty or edible than they did waxed fruits. Among waxed fruit, the flavor of the sprayed fruit was similar to that of the experimental formulation with $15 \%$ solid matter. The flavor of fruit from the latter treatments, particularly from Zivdar wax, was close to that of unwaxed fruits (Table 2).

The respiration rate of fruit treated with the various wax formulations and modes of application was almost the same after storage and simulated retail handling. The rate was 20.8 $\mathrm{mg} \mathrm{CO} / \mathrm{kg}$ per $\mathrm{hr}$ in unwaxed fruit and 21.0 and $19.9 \mathrm{mg}$ $\mathrm{CO}_{2} / \mathrm{kg}$ per hr in Britex- and Zivdar-waxed fruits, respectively.

\section{Discussion}

Transpiration (moisture loss) and respiration are physiological processes involved in deterioration of citrus fruit after harvest (Purvis, 1983). Waxing the fruit is a practice aimed at reducing water loss (Newhall and Grierson, 1955). However, only a very thin film of wax should be applied, since thicker films can cause the development of fermentation odors and off-flavors in the fruit (Long and Leggo, 1959). We found that waxing 'Murcott' tangerine leads to increased internal $\mathrm{CO}_{2}$, ethanol, and conse-

able 1. Chemical ${ }^{\mathrm{z}}$, compositional ${ }^{\mathrm{y}}$, weight ${ }^{\mathrm{x}}$, and sensory ${ }^{\mathrm{w}}$ characteristics in 'Murcott' tangerine at harvest and after 2 or 4 weeks of storage at $5 \mathrm{C}$ plus 1 week of simulated retail handling at $17 \mathrm{C}$.

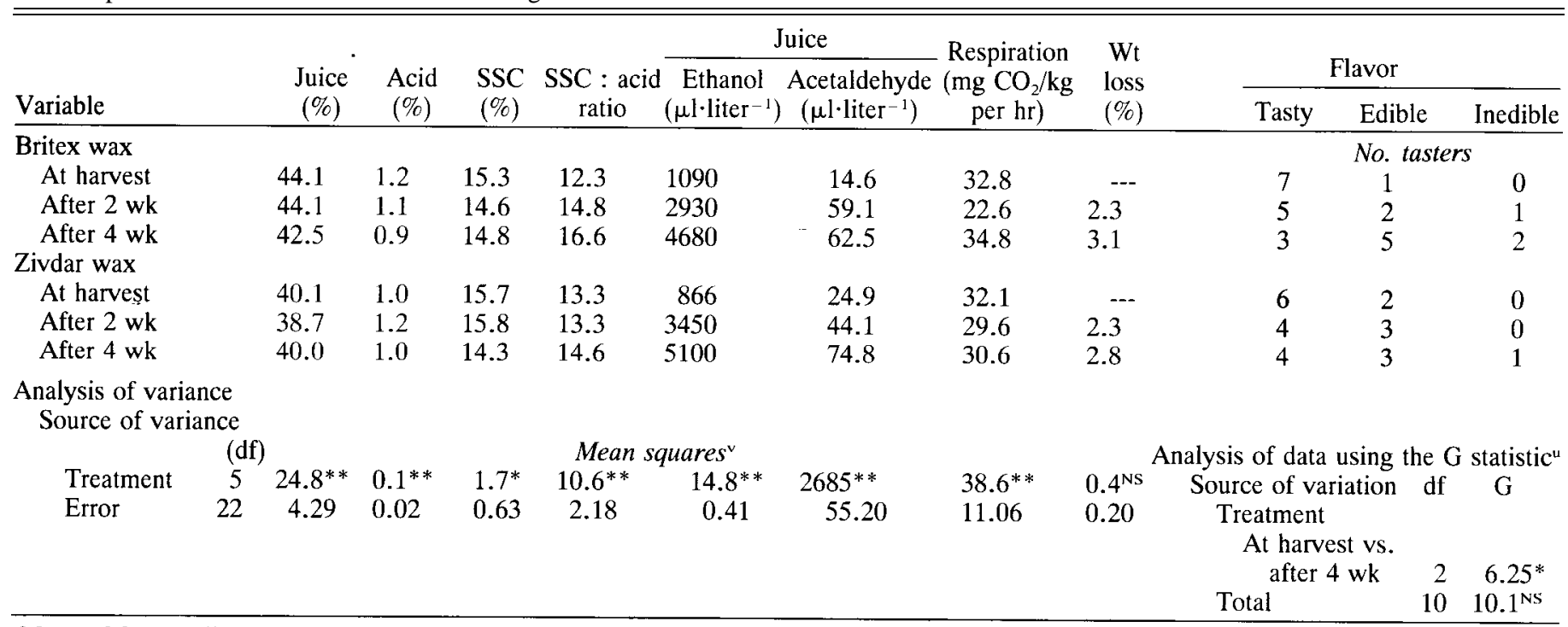

${ }^{2}$ Mean of four replicates of five fruits each.

yean of four replicates of eight to 10 fruits each.

${ }^{x}$ Mean of two replicates of 25 fruits each.

"Mean of two replicates of six to 10 tasters each.

vNS,**,* Nonsignificant or significant at $P=0.01$ or 0.05 , respectively.

uNS, * Nonsignificant or significant at $P>0.01$ by $\chi^{2}$. 
Table 2. Effect of waxes and application method on weight $\operatorname{loss}^{2}$, ethanol and acetaldehyde (AA) concentrations in the juice' and in the internal atmosphere' and on sensory characteristics of 'Murcott' tangerine after 4 weeks of storage at $5 \mathrm{C}$ and 1 week of simulated retail handling at $17 \mathrm{C}$.

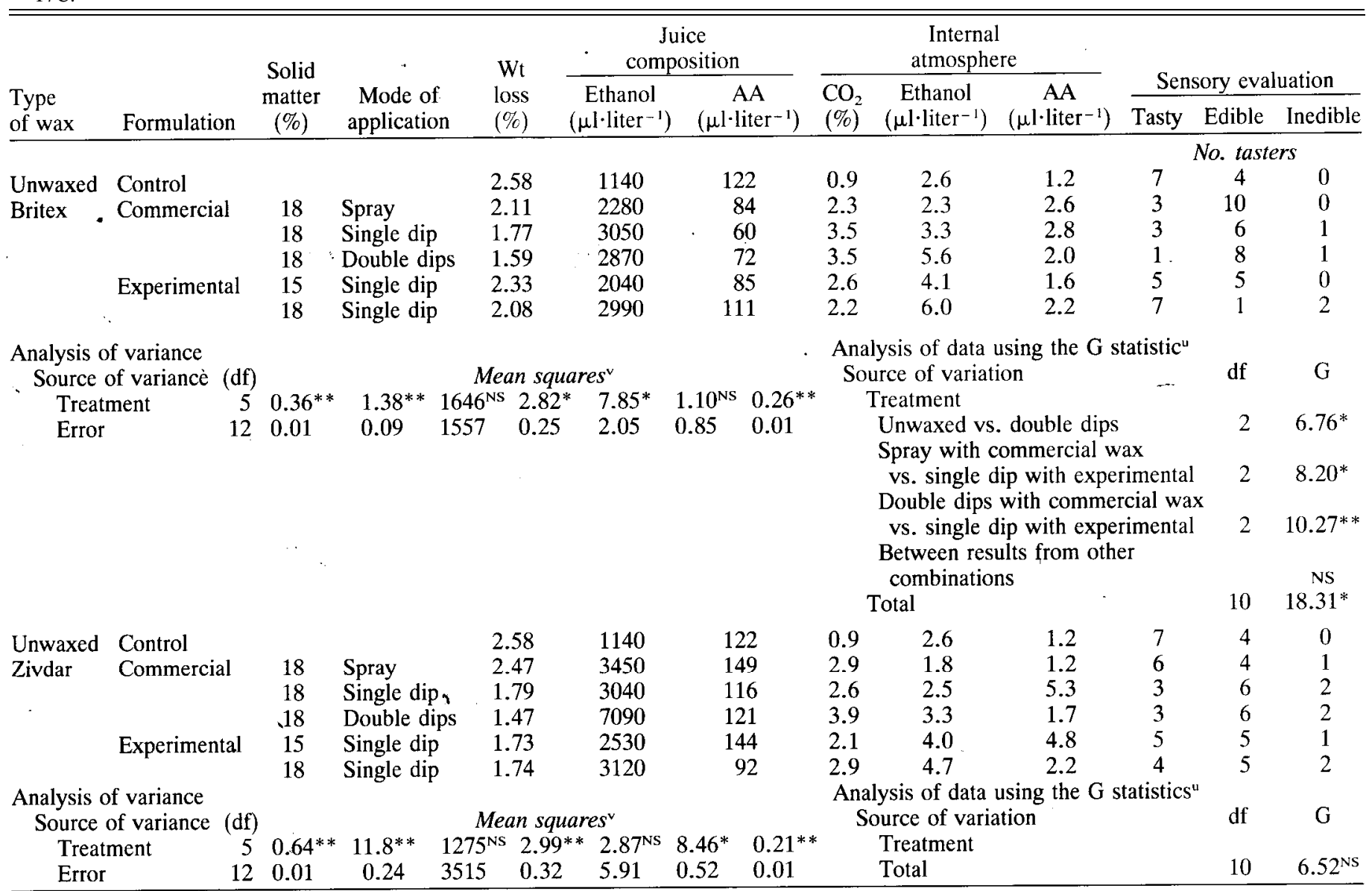

${ }^{\mathrm{z}}$ Mean of 25 fruits weighed individually.

y Mean of three replicates of five fruits each. Ethanol and AA contents at harvest were $131 \pm 21$ and $18 \pm 3 \mu l \cdot{ }^{-1 i t e r}{ }^{-1}$, respectively.

${ }^{x}$ Mean of three replicates of five fruits each.

"Mean of eight to 10 tasters.

vNS.**,**Nonsignificant or significant at $P=0.01$ or 0.05 , respectively.

uNs, * Nonsignificant or significant at $P>0.01$ by $\chi^{2}$.

quent off-flavor. Ben-Yehoshua (1969) found that the respiratory activity of waxed 'Shamouti' and 'Valencia' oranges declined and that internal $\mathrm{CO}_{2}$ rose during storage. Cuquerella et al. (1981) found that increased polyethylene in the wax composition resulted in increased internal $\mathrm{CO}_{2}$ and juice ethanol, as well as decreased internal $\mathrm{O}_{2}$ and water loss in 'Navel' and 'Valencia' oranges and in 'Clementine' tangerines. Commercial spray coatings and experimental formulations of wax with $15 \%$ solid matter were found to have greater transpiration and gas exchange, probably because there was less wax applied. This resulted in greater water loss and less flavor deterioration than in the other wax treatments examined. Volatiles (ethanol and acetaldehyde) in certain amounts are important components of the quality evaluation of fresh citrus fruit (Moshonas and Shaw, 1974; Norman, 1977; Nursten and Williams, 1967). While it seems that increases in ethanol level in fruit adversely affected the taste quality, the role of acetaldehyde change was not clear. Our results suggest that acetaldehyde improves fruit flavor, but this point requires further research for clarification.

\section{Literature Cited}

Ben-Yehoshua, S. 1969. Gas exchange, transpiration, and the commercial deterioration in storage of orange fruit. J. Amer. Soc. Hort. Sci. 94:524-528.

Cohen, E., Y. Shalom, and I. Rosenberger. 1985. The effect of growing area, rootstock, harvest time, waxing and storage temperatures on postharvest quality of Murcott fruit (in Hebrew with English summary). Hassadeh 66:70-74.

Cuquerella, J., J.M. Martinez-Javega, and M. Jimenez-Cuesta. 1981. Some physiological effects of different wax treatments on Spanish citrus fruit during cold storage. Proc. Intl. Sot. Citriculture 2:734737.

Davis, P.L. and W.G. Chace, Jr. 1969. Determination of alcohol in citrus juice by gas chromatographic analysis of headspace. HortScience 4:117-119.

Davis, P. L., W.G. Chace, Jr., and R.H. Cubbedge. 1967. Factors affecting internal oxygen and carbon dioxide concentration of citrus fruits. HortScience 2:168-169.

Davis, P.L. and R.C. Hoffmann. 1973. Effects of coatings on weight loss and ethanol buildup in juice of oranges. J. Agr. Food Chem. $21: 155-158$ 
Davis, P. L., B. Roe, and J.H. Bruemmer. 1973. Biochemical changes in citrus fruits during controlled atmosphere storage. J. Food Sci. 38:225-229.

Long, J.K. and D. Leggo. 1959. Waxing citrus fruits. Food Preservation Quart. 19:32-37.

Moshonas, M.G. and P.E. Shaw. 1974. Quantitative and qualitative analysis of tangerine peel oil. J. Agr. Food Chem. 22:282284.

Newhall, W.F. and W. Grierson. 1955. A low cost, self polishing, fungicidal water wax for citrus fruit. Fla. Agr. Expt. Sta. J. Ser. no. 396.

Norman, S.M. 1977. The role of volatiles in storage of citrus fruits. Proc. Intl. Soc. Citriculture 1:238-242.

Nursten, H.E. and A.A. Williams. 1967. Fruit aroma. Survey of components identified. Chem. Ind. 23:486-497.

Purvis, A.C. 1983. Moisture loss and juice quality from waxed and individually seal-packaged citrus fruits. Proc. Fla. State Hort. Soc. 96:327-329. 